\title{
The Effects of 6-week Handgrip Strengthening on the Rowing Performance of Young Male Oarsmen 青年男子賽艇學員接受六星期手握力訓練後對賽艇表現的影響
}

\author{
Robert Siu Kuen NG \\ Physical Education unit, \\ The Chinese University of Hong Kong, HONG KONG \\ 吳兆權 \\ 香港中文大學體育部

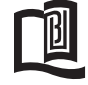

\begin{abstract}
The purposes of this study were to investigate (1) the contribution of the different muscular strength to the performance of 30-second indoor rowing maximal test (30-sec Test) and 6-minute indoor rowing all-out test (6-min Test); and (2) the effects of 6-week handgrip strength training on the performance of 30-secTest and 6-minTest. Twenty young male rowers (age: $14.7 \pm 1.2$ years, height: $172.4 \pm 7.7 \mathrm{~cm}$, weight: $66.3 \pm 8.9 \mathrm{~kg})$ were randomized $(\mathrm{n}=10)$ into the experimental and control groups. The experimental group performed 3 sets of 12 Repetition Maximum barbell wrist curl training 3 times per week for 6 weeks. A series of tests for muscular strength and the two rowing performances were carried out Pre and Post the training period. The results of 30-secTest was significant correlated with the sum of left and right handgrip strength (HGS) $(\mathrm{r}=$ $.76-.78 ; \mathrm{p}<.01)$ and the leg and back strength (LBS) $(r=.65-.66 ; \mathrm{p}<.05)$. Significant correlation was recorded between the performance of 6 -minTest and the LBS $(\mathrm{r}=.84 ; \mathrm{p}<.01)$, but not with the HGS. Results of a paired $\mathrm{t}$-test show that only the HGS improved significantly in the experimental group with an overall improvement of $9.6 \%(\mathrm{p}<.05)$ but produced no significant changes in the performance of 30-sec Test and 6-minTest.
\end{abstract}

Key words: handgrip strength, rowing performance, training

\section{摘 要}

本研究探討：(1)身體不同部位的肌力分別對30秒賽艇機極速測試(30秒測試)和6分鐘的賽艇機測試(6分鐘測試)表現之關係；(2) 在接受 6 星期手握力訓練後分別對 30 秒測試和6分鐘測試之表現的影響。採用實驗研究法, 隨機將20位男子賽艇學員分為實驗組和 對照組。結果表明：(1)腳和腰的肌力與雙手握力總和在 30 秒測試表現有直接關係。(2)只有腳和腰的肌力與6分鐘測試表現有直接相 關。另外, 實驗組經過6星期手握力訓練後, 雙手握力總和明顯增加了接近一成, 但分別對 30 秒測試和 6 分鐘測試表現沒有顯注的 提高。

關鍵詞：青年男子艇手、手握力、訓練、賽艇表現

\section{Introduction}

Rowing demands a high level of strength and endurance (Hagerman, 1984; Shephard, 1998). Aerobic metabolism has been reported to contribute $70-80 \%$ of the total energy expenditure of a $2000 \mathrm{~m}$ race whereas the remaining energy is supplied by anaerobic sources (Cosgrove,
Wilson, Watt \& Grant, 1999; Maestu, Jürimäe \& Jürimäe, 2005; Mickelson \& Hagerman, 1982; Pyne, Boston, Martin \& Logan, 2000; Russell, Le Rossignol \& Sparrow, 1998; Shephard, 1998).

Smith and Loschner (2002) summarized that the rowing performance depends on the rower's fitness and 
ability to optimize the application of forces on the oar handles, seat and stretcher. Power is generated from large to small muscle groups, the maximal power output and the overall work output may be limited by the strength of small muscle groups such as forearm. The group of forearm muscles plays an important role in rowing movement. It controls the gripping motion and the wrist movement, which helps to connect the force generated from the legs, back and arms to the oar handle and to control the blade motion in the rowing stroke. This multitask puts this muscle group at the greatest risk of injury. Forearm and wrist injuries were common for elite rowers (Hickey, Fricker \& McDonald, 1997) and novice rowers (Rumball, Lebrun, Di Ciacca \& Orlando, 2005).

So (2007) and his colleagues examined the muscle recruitment patterns in 6-minute continuous rowing among rowers with different training levels, and suggested that the sport and conditioning coaches should adjust the strength and conditioning training programmes for the rowers so that the weakness of the small muscle would not hinder the rowing performance.

The contribution of handgrip strength to rowing performance has received little attention in rowing research. To my knowledge, no published studies have been investigated the effects of handgrip strength training on rowing performance in young male rowers. Therefore, the aims of this study were (a) to investigate the correlation between different muscular strength and rowing performance of young male rowers and (b) to examine the effects of 6-week handgrip strength training on the rowing performance of young male rowers.

\section{Method and Procedures}

\section{Participants}

The 20 young male rowers (age: $14.7 \pm 1.2$ years, height: $172.4 \pm 7.7 \mathrm{~cm}$, weight: $66.3 \pm 8.9 \mathrm{~kg}$ ) were randomly $(\mathrm{n}=10)$ divided into experimental group and control group. They were from the intermediate level of the Youth Rowing Development Programme (YRDP) in Hong Kong. The dominant hand of all participants was right-handed, none of them had any musculoskeletal problems at the time of testing. Written informed consent was obtained from all participants and their parents after reading the testing procedures and potential risks associated with participation, and ethical approval was received from the university. A two group, pre-post design was used in this study to determine whether 6-week period of handgrip strength training would result in a statistical significant increase in rowing performances.

\section{Training}

The investigation period and data collection took place during their preseason training, when training emphasis was primarily focused on aerobic base (long duration and low intensity) and muscular strengthening. They had been training three days per week by the same coach with identical training programme. It consisted of rowing either on sculling boat or on a Concept II rowing ergometer and strength and conditioning training. It included 3 sets of 12 Repetition Maximum (RM) bench press, arm curl, arm extension, abdominal curl, back extension, leg extension, leg curl and squat. In addition to their normal strength and conditioning training programme, the rowers in the experimental group performed 3 sets of $12 \mathrm{RM}$ barbell wrist curl training three times per week for six weeks.

\section{Measurements}

The instruction and procedures of test were standardized and were administrated by one tester. All rowers were tested on site. The height (Martin metal anthropometer) and body weight (medical balance scale) of the rowers were measured to the nearest $0.1 \mathrm{~cm}$ and $0.1 \mathrm{~kg}$ respectively. Body mass index (BMI, $\mathrm{kg} \cdot \mathrm{m}-2)$ was calculated.

The sequence of tests was in random order. Before the assessment, a standard warm up procedure was performed, a demonstration was shown, and a familiar session was provided. Strong verbal encouragement was provided by the coach to all rowers during all tests. 
Table 1. The Physical and Training Characteristics of the Experimental and Control Groups.

\begin{tabular}{|c|c|c|}
\hline Physical and training data & $\begin{array}{l}\text { Experimental }(n=10) \\
\text { mean } \pm \text { sd }\end{array}$ & $\begin{array}{l}\text { Control }(\mathrm{n}=10) \\
\text { mean } \pm \mathrm{sd}\end{array}$ \\
\hline Mean age (years) & $14.9 \pm 1.7$ & $14.7 \pm 0.5$ \\
\hline Height $(\mathrm{cm})$ & $174.3 \pm 10.0$ & $170.2 \pm 3.2$ \\
\hline Body mass $(\mathrm{kg})$ & $68.2 \pm 10.5$ & $64.0 \pm 6.6$ \\
\hline BMI $\left(\mathrm{kg} \cdot \mathrm{m}^{-2}\right)$ & $22.3 \pm 1.5$ & $22.1 \pm 2.2$ \\
\hline Resting heart rate (beats/min) & $78.9 \pm 12.0$ & $68.5 \pm 7.0$ \\
\hline Rowing experience (years) & $1.2 \pm 0.8$ & $1.0 \pm 0.4$ \\
\hline Days training per week & $3.0 \pm 0.4$ & $3.1 \pm 0.2$ \\
\hline Water rowing per week (Hour) & $6.1 \pm 0.4$ & $5.9 \pm 0.3$ \\
\hline Ergometer training per week (Hour) & $2.6 \pm 0.3$ & $2.8 \pm 0.5$ \\
\hline Weight training per week (Hour) & $2.9 \pm 0.6$ & $2.5 \pm 0.7$ \\
\hline
\end{tabular}

\section{Handgrip strength test}

Participants were seated with the elbow of the testing hand resting on a table. The Jamar Hydraulic Hand Dynamometer (Model PC5030J1, Lafayette Instrument, Inc., Lafayette, IN) was adjusted for each participants so that the angle of flexion of the middle finger at the second joint from the tip was as close to 900 as possible. Participants were instructed to squeeze the dynamometer with maximum effort for each trial and the effort was recorded to the nearest $0.1 \mathrm{~kg}$. The tested wrist of the participants was maintained at a neutral position and no part of the dynamometer were touched the table during the measurements. No other body movement was allowed. Successive trials were done on alternating hands with at least 30 seconds of rest between trials. Three trials for each hand were performed and the maximum value was used for data analysis. The left and right hand reliability coefficients between the three trials were $r=.88$ and .86 respectively.

\section{Leg and Back Strength test}

A leg and back dynamometer (Baseline) was used to measure the static leg and back strength. The participants gripped the handle of the dynamometer with the palms facing toward the body and stood on the dynamometer platform. The chain attached to dynamometer and the handle was adjusted so that the arms were straight and the knees were bent at approximately 1100. They exerted a maximum force straight upward by extending their legs. They kept their head erect, chest high, arms and back straight. Three trials were assessed to the participants with at least 30 seconds of rest between trials and the best score was taken. The test-retest reliability coefficients between the three trials were $r=.78$.

\section{Standing Vertical High Jump test}

Vertical reach was measured and marked with chalk by having each participant stand with his dominant side next to a wall. With feet on the ground, and hip as close as possible to the wall, the participant extended the arm closest to the wall and reached as high as possible without allowing any part of the feet to lose contact with the ground. The vertical jump of the participants was measured after they were instructed to stand with their dominant side next to the wall, with feet shoulder-width apart. The participants were instructed to perform a vertical jump using their dominant hand and marked with chalk while at the top of their jump. Three vertical jumps were allowed, with the highest jump recorded. The height of the jump was the difference between the vertical reach and the vertical jump. The test-retest reliability coefficients between the three trials were $\mathrm{r}=.85$.

\section{0 -second indoor rowing maximal test and 6-minute indoor rowing all out test}

All participants trained and were tested regularly on Concept II rowing ergometers. The ergometer was selfcalibrated and the vane of the ergometer was kept fully closed for each test. The participants were free to select their own stroke rate, and were encouraged by their coach to exercise at a stroke rate that they were accustomed to during competition. After a self-selected warm up, the rowing performance was assessed in 30-second indoor rowing maximal test and 6-minute indoor rowing all out test on the same rowing ergometer (Concept II ModelC Inc., Morrisville, VT). The intensity and work done of each stroke was indicated as the power output and distance traveled in the monitor. The distance and average 
power output were reported in both tests, while the peak power output was measured in 30-second indoor rowing maximal test. The test-retest reliability coefficients were $r$ $=.72$ and $\mathrm{r}=.76$ for 30 -second indoor rowing maximal test and 6-minute indoor rowing all out test respectively.

\section{Statistical analysis}

To compare the selected physiological variables of experimental and control groups, A paired t-test was performed to determine whether significant increases occurred within each group from the pre-test to posttest. Pearson Product-Moment correlation coefficients were used to determine the muscular strength and relationships between each of the independent variables, the maximal and average power output and work done in 30-second indoor rowing maximal test, and the average power output and the work done in 6-minute indoor rowing all out test. Percent difference was computed as follows: (pre-test - post-test) / pre-test X 100. All analyses were performed using SPSS version 18.0 (SPSS INC., Chicago.IL) with the significance level for all analyses set at $\mathrm{p}<.05$.

\section{Results}

Table 2 displayed that the 30 -second indoor rowing performance was significant correlated with the left + right handgrip strength $(\mathrm{r}=.76-.78 ; \mathrm{p}<.01)$ and the leg and back strength $(r=.65-.66 ; \mathrm{p}<.05)$. Significant correlation was recorded between the 6-minute indoor rowing performance and the leg and back strength $(\mathrm{r}=.84 ; \mathrm{p}<.01)$, whereas there was no significant correlation between the left + right handgrip strength and the 6-minute indoor rowing performance $(\mathrm{p}>.05)$. Correlation between the standing vertical high jump height and the two rowing test performances was found not to be significant $(\mathrm{p}>.05)$.

Table 2. Inter Correlation among Physiological Variables and Rowing Ergometer Performance of Young Male Rowers $(\mathrm{n}=\mathbf{2 0})$.

\begin{tabular}{llllll}
\hline & \multicolumn{2}{l}{ 30-second indoor rowing maximal test } & & 6-minute indoor rowing all out test \\
\hline Variables & Total distance & Peak power & Average power & Total distance & Average Power \\
\hline $\begin{array}{l}\text { Left }+ \text { Right } \\
\text { handgrip strength }\end{array}$ & $.776^{* *}$ & $.768^{* *}$ & $.758^{* *}$ & .542 & .534 \\
$\begin{array}{l}\text { Leg and back } \\
\text { strength }\end{array}$ & $.651^{*}$ & $.649^{*}$ & $.664^{*}$ & $.840^{* *}$ & $.839^{* *}$ \\
$\begin{array}{l}\text { Standing vertical } \\
\text { high jump }\end{array}$ & .291 & .130 & .290 & .270 & .274 \\
\hline
\end{tabular}

$* \mathrm{p}<.05 \quad * * \mathrm{p}<.01$

After 6-week of barbell wrist curl training for the experimental group, the total handgrip strength improved significantly by $9.6 \%(\mathrm{p}<.05)$, whereas for the control group it improved $2.0 \%$ but was not statistical significant. A paired t-test showed no significant difference for the pre and post training tests in the experimental and control groups for leg and back strength $(\mathrm{p}>.05)$, standing vertical high jump height $(\mathrm{p}>.05)$, 30-second maximal test performance $(\mathrm{p}>.05)$ and 6 -minute all out test performance $(\mathrm{p}>.05)$. 
Table 3. Strength Test Results, Vertical High Jump Distance and Rowing Performance of the Experimental and Control Group (mean \pm sd).

\begin{tabular}{|c|c|c|c|c|c|c|}
\hline \multirow[t]{2}{*}{ Test items } & \multicolumn{3}{|c|}{ Experimental $(n=10)$} & \multicolumn{3}{|c|}{ Control $(\mathrm{n}=10)$} \\
\hline & Pre-test & Post-test & $\%$ diff & Pre-test & Post-test & $\%$ diff \\
\hline Left + Right handgrip strength $(\mathrm{kg})$ & $81.9 \pm 16.8$ & $89.4 \pm 19.9^{*}$ & 9.6 & $75.5 \pm 14.6$ & $77.0 \pm 15.6$ & 2.0 \\
\hline Leg and back strength $(\mathrm{kg})$ & $90.7 \pm 18.2$ & $93.4 \pm 18.8$ & 3.0 & $69.7 \pm 12.8$ & $74.2 \pm 10.1$ & 6.5 \\
\hline $\begin{array}{l}\text { Standing vertical high jump (cm) } \\
30 \text {-second maximal test }\end{array}$ & $47.0 \pm 5.4$ & $49.9 \pm 5.7$ & 6.1 & $48.0 \pm 3.2$ & $49.3 \pm 5.0$ & $\begin{array}{l}2.8 \\
-1.4\end{array}$ \\
\hline Distance $(\mathrm{m})$ & $160.1 \pm 10.5$ & $159.9 \pm 8.6$ & -0.2 & $153.3 \pm 9.1$ & $151.2 \pm 12.1$ & \\
\hline Peak power output (watt) & $524.4 \pm 105.0$ & $502.0 \pm 73.2$ & -4.3 & $453.7 \pm 90.7$ & $439.3 \pm 111.0$ & -3.2 \\
\hline Average power output (watt) & $432.3 \pm 85.0$ & $426.9 \pm 71.7$ & -1.3 & $377.2 \pm 67.4$ & $368.0 \pm 87.9$ & -2.4 \\
\hline Average rating (strokes/min) & $47.7 \pm 3.4$ & $47.7 \pm 8.4$ & 0 & $47.7 \pm 5.0$ & $46.2 \pm 7.1$ & -3.2 \\
\hline 6-minute all out test & & & & & & \\
\hline Distance (m) & $1576.9 \pm 61.2$ & $1587.4 \pm 57.8$ & 0.7 & $\begin{array}{l}1465.0 \quad \pm \\
82.5\end{array}$ & $1485.0 \pm 103.2$ & 1.2 \\
\hline Average power output (watt) & $236.1 \pm 27.8$ & $241.0 \pm 26.3$ & 4.9 & $190.2 \pm 33.1$ & $197.5 \pm 44.5$ & -3.9 \\
\hline Average rating (strokes/min) & $28.3 \pm 1.9$ & $28.4 \pm 2.4$ & 0.5 & $27.7 \pm 1.8$ & $26.8 \pm 0.4$ & -3.0 \\
\hline
\end{tabular}

$* \mathrm{p}<.05$

\section{Discussion}

The results of this study indicated that the rowing performance in 30-second and 6-minute did not significantly improve, although the handgrip strength in the experimental group significantly increased after 6-week barbell wrist curl training. This shows that the improved isometric handgrip strength did not contribute significantly to the 30-second and 6-minute rowing performances of young male rowers. This is in line with the review summarized by Lawton, Cronin and McGuigan (2011) that the isometric strength of a specific muscle group and the repetition endurance tests of the arms did not predict the performance of dynamic rowing motion precisely. Future research can be carried out to investigate whether the similar results were obtained with different backgrounds of rowers such as different weight categories, level of training and gender.

In the present study no rower complained the fatigue of muscles in forearm and calves after the rowing tests. This is in variance with the findings of So (2007) and his colleagues that with less experienced rowers, all muscles are used from the start with early fatigue of small muscle groups such as muscles of the arms and calves. It was unclear whether the onset of fatigue of small muscle groups such as forearm might be delayed as a result of handgrip strengthening. Further studies may consider using electromyography for evaluating the recruitment pattern of muscles which involved in the rowing motion.
There are some limitations in the study. The changes of aerobic and anaerobic power were not measured pre and post the training period which is demonstrated contributing significantly to the rowing performance (Cosgrove, Wilson, Watt \& Grant, 1999; Mickelson \& Hagerman, 1982; Pyne, Boston, Martin \& Logan, 2000; Russell, Le Rossignol \& Sparrow, 1998; Shephard, 1998). Moreover, any shift of the muscle recruitment pattern and the contribution of the different muscles during the rowing motion were not monitored in the rowing test.

\section{Conclusions}

The handgrip strength training period of 6-week produced significant positive changes in isometric handgrip strength, but did not enhance the 30-second and 6-minute rowing performances in young male rowers.

\section{Practical Applications}

It is recommended that handgrip strengthening should be included in the strength and conditioning training in order to prevent injury and early fatigue of forearm muscles in the rowing activity.

\section{Acknowledgements}

The author wish to thank Mr. Chan Chung Lung, Jacky for data collection and the oarsmen for their participation. No funding was received for this study. 


\section{References}

Celik, O., Sukran, N.K., Korkusuz, F., \& Bozkurt, M. (2005). Reliability and validity of the modified Conconi test on Concept II rowing ergometers. Journal of Strength and Conditioning Research, 19(4), 871-877.

Cosgrove, N.J., Wilson, J., Watt, D., \& Grant, S.F. (1999). The relationship between selected physiological variables of rowers and rowing performance as determined by a $2000 \mathrm{~m}$ ergometer test. Journal of Sports Science, 17, 845-852.

Craven, R.P., Kinch, R.FT., Parker, D.F., \& Walter, S. J. (1993). Stroke analysis using a modified Concept II rowing ergometer. Journal of Physiology, 459, 133p.

Hagerman, F.C. (1984). Applied physiology of rowing. Sports Medicine, 1, 303-326.

Hickey, G.J., Fricker, P.A., \& McDonald, W.A. (1997). Injuries to elite rowers over 10-yr period. Medicine Science and Sports Exercise, 29(12), 1567-1572.

Lawton, T.W., Cronin, J.B., \& McGuigan, M.R. (2011). Strength testing and training of rowers: a review. Sports Medicine, 41(5):413-432.

Maestu, J., Jürimäe, J., \& Jürimäe, T. (2005). Monitoring of performance and training in rowing. Sports Medicine, 35(7), 597-617.

Mathiowetz, V., Weber, K., Volland, G., \& Kashman, N. (1984). Reliability and validity of hand strength evaluation. Journal of Hand Surgery, 9A, 222-226.

Mickelson, T.C., \& Hagerman, F.C. (1982). Anaerobic threshold measurements of elite oarsmen. Medicine and Science in Sports and Exercise, 14, 440-444.

Pyne, D.B., Boston, T., Martin, D.T., \& Logan, A. (2000). Evaluation of the Lactate Pro blood lactate analyzer. European Journal of Applied Physiology, 82, 112-116.

Rodriguez, R.J., Rodriguez, R.P., Cook, S.D., \& Sandborn, P.M. (1990). Electromyographic analysis of rowing stroke biomechanics. Journal of sports Medicine and Physical Fitness, 30, 103-108.
Rumball, J.S., Lebrun, C.M., Di Ciacca, S.R., \& Orlando, K. (2005). Rowing injuries. Sports Medicine, 35(6), 537555 .

Russell, A.P., Le Rossignol, P.F., \& Sparrow, W.A. (1998). Prediction of elite schoolboy 2000-m rowing ergometer performance from metabolic, anthropometric and strength variables. Journal of Sport Science, 16, 749-754.

Shephard, R.J. (1998). Science and medicine of rowing: A review. Journal of Sports Science, 16, 603-620.

Smith, R.M., \& Loschner, C. (2002). Biomechanics feedback for rowing. Journal of Sports Science, 20, 783-791.

Smith, R.M., \& W.L. Spinks (1995). Discriminant analysis of biomechanical differences between novice, good and elite rowers. Journal of Sports Science, 13, 377385 .

Womack, C.J., Davies, S.E., Wood, C.M., Sauer, K., Alvares, J., Weltman, A., \& Gaesser, G.A. (1996). Effects of training on physiological correlates of rowing ergometry performance. Journal of Strength Conditioning Research, 10, 234-238.

\section{Correspondence:}

Robert Siu Kuen NG, PhD

Physical Education Unit,

The Chinese University of Hong Kong,

Shatin, New Territories, Hong Kong

Tel: (852) 91214443

Fax: (852) 26035275

E-mail: sarobert1218@gmail.com 